\title{
Rational Liquid Cooling Systems of Internal Combustion Engines
}

\author{
Yuryi Moshentsev ${ }^{1}$, Oleksiy Gogorenko', Olha Dvirna2 ${ }^{2 *}$ \\ 1 Department of Internal Combustion Engines, Installations and Technical Operation, Admiral Makarov \\ National University of Shipbuilding, 9, Heroiv Ukraine Ave., Mykolaiv, 54007, Ukraine \\ 2 Department of Engineering Sciences, Faculty of Marine Engineering, Gdynia Maritime University, 81-87 \\ Morska St., 81-225 Gdynia, Poland \\ * Corresponding author's email: o.dvirna@wm.umg.edu.pl
}

\begin{abstract}
The scheme of the cooling system is considered, which can be the basis for creating the most efficient cooling systems for IC engines of any purpose. It is assumed that the use of any other scheme is devoid of a rational basis. The scheme consists of two connected circulation circuits, in one of which the coolant flow rate is an order of magnitude less than in the second. The engine is included in a circuit with increased coolant flow. All heat exchangers are in the second circuit. Rules for the formation of such systems are formulated. The basis of the method for calculating such systems is considered. It is indicated that the flow rate through each heat exchanger must be determined by calculation to ensure the maximum efficiency of the cooling system. The considered scheme allows to provide the maximum possible depth of charge air cooling, if its temperature is not specified, or to ensure the minimum cost and compactness of the cooling system; if this temperature is known. The scheme allows regulating the temperatures of the cooling fluids of the system with all kinds of changes in the engine operating conditions and the ambient temperature.
\end{abstract}

Keywords: charge air cooler, cooling systems, heat transfer surface, Internal combustion engines, oil cooler, low-flow system.

\section{INTRODUCTION}

Liquid dual-circuit cooling systems for IC engines are currently being implemented based on various schemes. The use of different schemes leads to different results, and, therefore, it is possible to distinguish between rational and irrational schemes. At the same time, there is a scheme which all the problems associated with the creation of a highly efficient recuperative liquid cooling system are solved. If to follow the proposed rules for the formation of such schemes, it is possible to form several options that will have differences in the schemes, but at the same time will be similar in their indicators. The resulting options may be more or less convenient for manufacturers of engines for various purposes.

Using the proposed scheme will not lead to good results if its implementation does not consider the design features of heat exchangers and the features of determining the flow rate of the heat carrier through its. This article considers the proposed scheme as the most promising and explains the features of its creation and application. Proper use of the scheme and its features allows to provide the maximum possible cooling depth of charge air or, if the air temperature in the receiver is set, to obtain the minimum possible dimensions, weight and cost of the cooling system. In particular, even with a rational design of the system scheme, irrationally selected flow rates of the coolant flowing through various heat exchangers (within the range of possible changes) can increase the total mass of the heat exchanger cores (and, accordingly, the cost) of the system by $15-20 \%$. The magnitude of the decrease in the depth of cooling of the charge air in this case (compared with a system in which the costs are 
rationally selected) can be more than $25-30 \mathrm{~K}$. For systems with irrational schemes, the magnitude of the increase in core mass or the magnitude of the decrease in the depth of cooling of the charged air can even be big ones.

\section{ANALYSIS OF THE NEWEST RESEARCHES AND PUBLICATIONS}

Liquid recuperative cooling systems are the most common for IC engines of almost all power and any purpose. All of them are double-circuit, where the cooling of the engine elements occurs with liquid circulating in a closed, internal circuit, and heat is removed from this circuit to water (for ship) or to air (for ground vehicles) through a special heat exchanger (radiator). Under certain conditions and for certain power plants, all of them can be applied and are applied up to the present [1-8].

The cooling systems currently in use are very diverse. Different cooling systems provide different system parameters. Cooling system parameters have a significant impact on the characteristics and main indicators of engines [9]. A lot of works is are devoted to the development of innovative cooling systems for passenger car engines [10]. Systems with such a scheme in which there is one circulation circuit can be considered the oldest. In them, the coolant of the internal circuit (ICC) sequentially moves through the engine and all heat exchangers, with the same flow rate everywhere. In such systems, ICC and oil were well cooled, they were well regulated, but the cooling depth of charge air was low. Then there were schemes of cooling systems in which the system was divided into two separate circuits [11]. In one of them (high- temperature circuit) there was an engine. In another (low- temperature circuit) was a charge air cooler. Such systems provided deep cooling of the charge air, but the separation of the circuits and the presence of two pumps made it difficult to regulate them depending on the operating conditions of the installation and ambient temperatures. The above system designs are considered, for example, in [1$5,12]$. For such schemes, studies have been carried out that have established the feasibility of determining the a flow rate of ICC in a closed simple circuit, depending on several factors determining the structure of this circuit and its operation [13, 14]. Empirical dependencies have been proposed to calculate the optimal ICC flow rate for such circuits [14]. It turned out that the flow rate of ICCs in this case turned out to be small compared to its expenses through the engine.

Then systems appeared in which the internal circuit with the ICCs was not divided into separate circuits, and for local cooling of the charge air, ICC was supercooled, which provided an increase in the cooling depth of the charge air and improved the control capabilities of such a system. In this case, the temperature of the ICC in front of the engine was maintained at the required level due to the mixing of various flows $[6-8,15]$. It was mentioned that in similar cooling systems the flow rate of ICC through heat exchangers should be very low, and the speed of ICC in the channels of heat exchangers should be reduced due to the relatively large number of strokes of ICC in such heat exchangers. The name «low-flow» was even proposed for such systems. However, another name for such systems is known - «systems with local subcooling». Thus, a tendency towards a certain change in engine cooling systems was clearly outlined so that the system was simple, adaptive and deeply cooled the charge air.

At the same time, modern engine cooling systems continue to be built on very different principles, while some of them do not have sufficient justification. For example, systems are known in which a charge air cooler has two cores, in the first of them, along with the air, it is cooled by ICC from a hotter circuit, and in the second from a colder circuit [2]. There are complex schemes in which the recycled gas is first cooled by air in an air-gas heat exchanger, and then further cooled in a liquid cooler [1]. There are complex schemes where a large cooling depth is provided by the use of additional, special devices [16-20]. It should be noted that the available information about such systems is more of an advertising nature, not revealing neither the place of these systems among others, nor the methods of their creation, nor their cost or compactness, nor how to create efficient and economical systems are considered.

It seems to the authors that the evolution of the schemes of liquid cooling systems at this time has led to a framework that can be general and rationale for all engines of any power and any purpose, without exception. Such schemes should be built according to certain rules, and the method for determining the flow rate of ICC through heat exchangers should be clear. In this case, certain differences are possible, which will be mentioned below. 


\section{PROBLEM SETTING}

The experience of designing and researching cooling systems shows that there is a great variety of them. In many cases, the choice of the scheme is determined by technological and other reasons. Many technical solutions are used to represent a consensus between the possible advantages and disadvantages of manufactured designs. At the same time, the observed solutions are sometimes difficult to explain to an outside researcher. For the development of new schemes of cooling systems to be carried out on a rational basis, it seems to us that it is necessary to highlight such a basis for the formation of a rational scheme of cooling systems, in which the main problems facing the creators of such schemes are solved. Apparently, the rational basis of the cooling system should ensure the minimum sum of the masses of the cores of all heat exchangers at the given coolant temperatures or the maximum decrease in the charge air temperature, all other things being equal. The scheme of such a system should be built according to certain rules.

\section{SYSTEM DESCRIPTION AND ASSUMPTIONS}

Such a scheme is shown in Figure 1 for a land vehicle (heat dissipates into the air through a radiator), but can also be used for ships when replacing a radiator with a water-to-water cooler.

The circuit has one ICC pump and one fan for cooling air (there can be several of them for parallel operation of fans). The fan pumps air through the radiator (in Figure 1, the radiator consists of two parallel sections).

The cooling system is divided into two communicating circulation circuits - with a fixed flow rate of the coolant and with a determinable flow rate (names proposed by the authors). The circuit with a fixed flow rate in Figure 1 is highlighted by a blue line. It includes an ICC pump and engine. The determinable flow rate circuit includes all heat exchangers. The circuits have common points: point A (discharge of a part of the ICC to the radiator, into a circuit with a determined flow rate) and point $\mathrm{B}$ (merging of ICC flows from bypass on the engine and all heat exchangers). From point B, ICC with a flow rate $G_{w e}$ enters the pump inlet.
All pump flow rate passes through the engine. After engine cooling, the ICC is divided into two unequal parts: the smaller part goes to the radiator, entering the circulation circuit with a determinable flow rate, and the majority returns to the ICC pump inlet through the bypass. The flow rates of ICC, in this case, are set by valves $1-4$. A smaller part of the ICC flow rate, $G_{w r}$, enters the circuit with a determinable flow rate and passes through the radiator, where it is cooled to a temperature of $t_{w 1}$. Then the ICC goes to heat exchangers: charge air coolers (in the diagram there are two simultaneously operating CACs), an oil cooler (OC) and a hydraulic fluid cooler (H). The flow rate of ICC through each heat exchanger is different and, when setting up the system, it is adjusted by dampers $2-4$. After heat exchangers, ICC flows are mixed and from the bypass flow on the engine, and then fed to the pump inlet. In a circuit with a determinable flow rate, the flow rate of ICCs through heat exchangers is significantly less than the pump flow rate.

For this example, the consumption of ICC through the engine is significantly greater than the consumption of ICC through heat exchangers. In principle, for different engines, different ratios of ICC flow rate through the engine and heat exchangers are possible. If the flow rate through the engine is less than the flow rate through the heat exchangers, then the pump must have an excess flow rate, and the circuit is supplemented bypassing part of the flow rate of the pump past by the engine.

At fractional loads and idling, as well as when the ambient temperature changes, thermostats $5-8$, the radiator shutters, and (possibly) the fan speed controller work. This provides temperature regulation of coolants in the system. In particular, it is possible to maintain temperatures of water, oil and hydraulic fluid in front of the engine, close to constant values at any possible changes in engine load and ambient temperature. It is also possible rational regulation of air temperature in the receiver of the engine depending on changes in these conditions.

All heat exchangers of the system have designs close to traditional ones, although the low-flow rate of ICC through them implies an increase in the number of strokes of ICC that exceeds traditional values.

Shell-and-tube heat exchangers with segmented diaphragms were proposed as water-oil coolers OC and coolers of hydraulic fluid $\mathrm{H}$. In heat exchangers, either a counter flow of coolants 


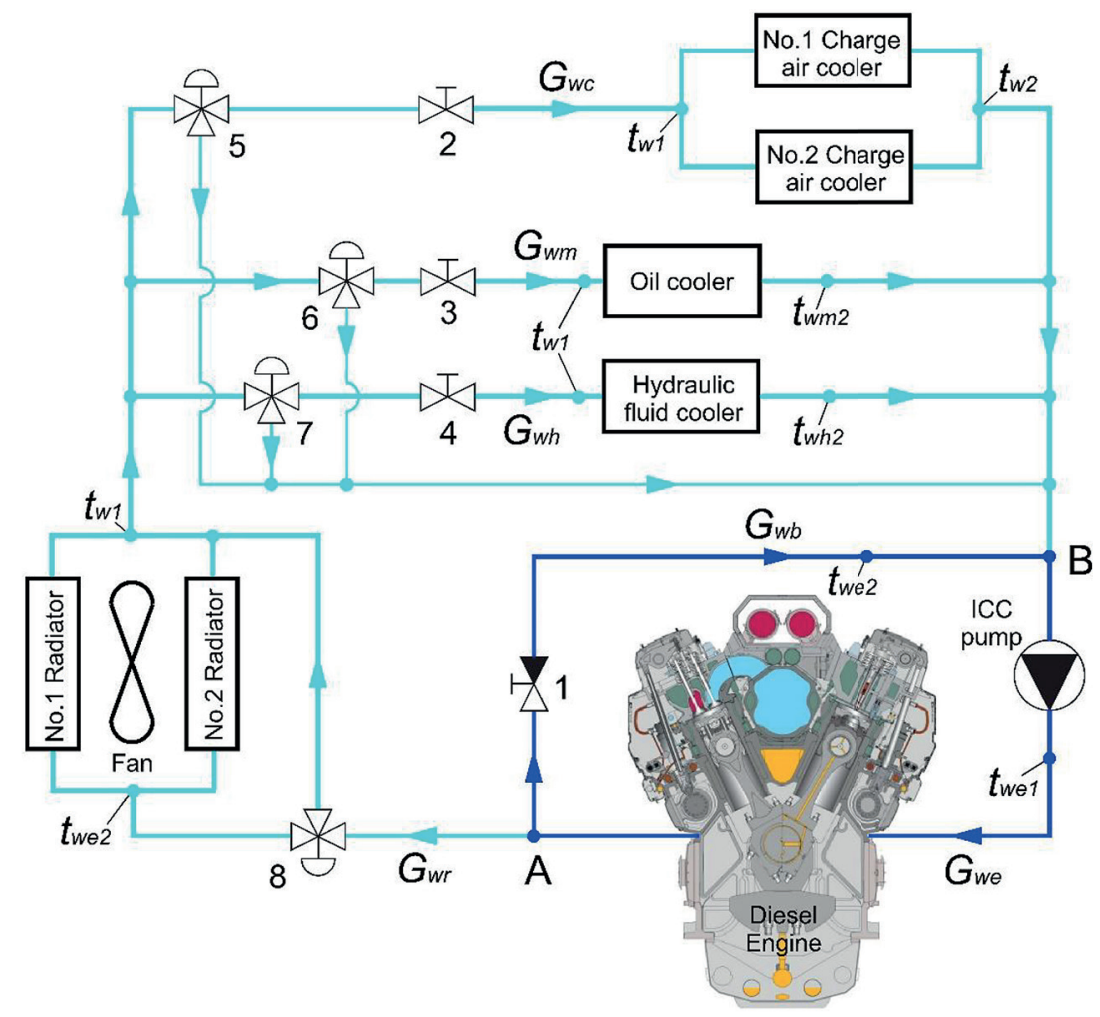

Fig. 1. Diagram of a low-flow rate cooling system with one pump and two circulation circuits

is realized with a single stroke of oil or hydraulic fluid and multiple cross-flow of ICC, or a reverse current in one heat exchanger, or multiple reverse currents in several heat exchangers with a common counterflow. The ICC flow moves transversely to the tube flow (outside the bundle). Coolant flows inside the tubes. Mutual flow schemes were implemented depending on the selected flow rate of the ICC through these heat exchangers. As a heat exchange surface for them, staggered bundles of tubes, ribbed by knurling (Figure 2), with the geometric dimensions given in Table 1, are proposed.

$\mathrm{CAC}$ has one single core. An increase in the number of strokes in heat exchangers is accompanied by a decrease in the coolant velocity in their channels. Differences in coolant speeds and in the number of strokes affect the efficiency of the heat exchangers in different directions and, as a rule, cancel each other out. The CAC is made in the form of a shell-box heat exchanger, in which a multiple cross-cross currents of coolants is are realized with a general counterflow. The coolant flows do not mix in the course of their movement within one stroke. The stream of water moves across the stream of air. The water flow moves from the air outlet to the inlet, when it flows repeatedly crosses the airflow. The mixing of the coolant takes place between the passes of the ICC.

The in-line tube bundle of flat-oval tubes with group transverse ribbing by flat plates having a stamped transverse triangular protrusion was considered as a heat exchange surface (Figure 3 ). The main geometrical parameters of the heat exchange surface are presented in Table 2.

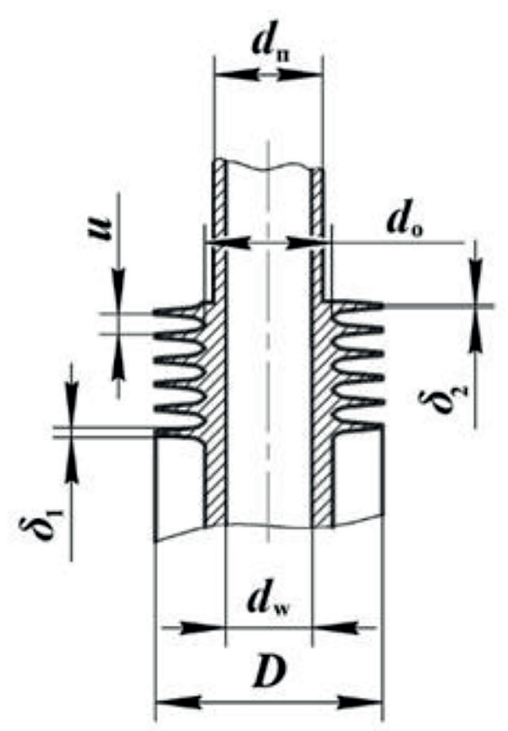

Fig. 2. Finned tube heat exchange surface for heat exchangers $\mathrm{OC}$ and $\mathrm{H}$ 
Table 1. Basic geometric parameters of the heat exchange surface of $\mathrm{OC}$ and $\mathrm{H}$ beams

\begin{tabular}{|l|c|c|}
\hline \multicolumn{1}{|c|}{ Items } & Designation & Values \\
\hline $\begin{array}{l}\text { Outer diameter of finning } \\
(\mathrm{mm})\end{array}$ & $\mathrm{D}$ & 24.5 \\
\hline Bearing tube diameter $(\mathrm{mm})$ & $\mathrm{d}_{\mathrm{o}}$ & 12.5 \\
\hline Tube inner diameter $(\mathrm{mm})$ & $\mathrm{d}_{\mathrm{w}}$ & 10 \\
\hline Step between ribs $(\mathrm{mm})$ & $\mathrm{u}$ & 2 \\
\hline $\begin{array}{l}\text { Rib thickness at the base } \\
(\mathrm{mm})\end{array}$ & $\delta_{1}$ & 0.55 \\
\hline Rib thickness at apex $(\mathrm{mm})$ & $\delta_{2}$ & 0.2 \\
\hline $\begin{array}{l}\text { Step between tubes, } \\
\text { perpendicular to oil } \\
\text { movement (mm) }\end{array}$ & $\mathrm{S}_{1}$ & 27 \\
\hline $\begin{array}{l}\text { Step between transverse } \\
\text { rows of pipes (mm) }\end{array}$ & $\mathrm{S}_{2}$ & 23.4 \\
\hline $\begin{array}{l}\text { Tubular breakout angle } \\
\text { (degrees) }\end{array}$ & $\theta$ & 30 \\
\hline
\end{tabular}

The design of the $\mathrm{R}$ (radiator) is close to the design of the CAC. It is assumed that the radiator blocks are of a design, each of which has one single core. The main difference between radiators and CAC is in the proportions of the main dimensions. Radiators have a shallow airflow depth. The air resistance of each radiator is no more; than $60 \mathrm{~mm} \mathrm{H}_{2} \mathrm{O}$ at atmospheric pressure.

The heat exchange surface of the radiator cores, in this case, is the same as in the CAC. On the engine under consideration, the radiators are located in two blocks operating in parallel (Figure 1).

\section{MATERIALS AND METHODS}

When constructing the proposed scheme, the following rules were used.

- The engine is pumped by the flow rate of ICC equal to the value set by the manufacturer when refining it.
Table 2. Basic geometric parameters of the heat exchange surface of CAC and R beams

\begin{tabular}{|l|c|c|}
\hline \multicolumn{1}{|c|}{ Items } & Designation & Values \\
\hline $\begin{array}{l}\text { Tube cross-section height } \\
(\mathrm{mm})\end{array}$ & $d_{w}$ & 3.8 \\
\hline $\begin{array}{l}\text { Step between corrugations } \\
\text { along with the air in one row } \\
(\mathrm{mm})\end{array}$ & $S$ & 23 \\
\hline $\begin{array}{l}\text { Distance between tubes in } \\
\text { a transverse row }(\mathrm{mm})\end{array}$ & $S_{1}$ & 10 \\
\hline $\begin{array}{l}\text { Step between transverse } \\
\text { rows of tubes }(\mathrm{mm})\end{array}$ & $S_{2}$ & 23 \\
\hline $\begin{array}{l}\text { Maximum cross-sectional } \\
\text { dimension of the tube }(\mathrm{mm})\end{array}$ & $S_{3}$ & 17 \\
\hline Spacing between ribs $(\mathrm{mm})$ & $S_{4}$ & 2.05 \\
\hline Tube wall thickness $(\mathrm{mm})$ & $\delta_{s t}$ & 0.4 \\
\hline Finning plate thickness $(\mathrm{mm})$ & $\delta_{p l}$ & 0.08 \\
\hline Corrugation width $(\mathrm{mm})$ & $e$ & 5 \\
\hline $\begin{array}{l}\text { Corrugation height from } \\
\text { surface (mm) }\end{array}$ & $h_{g}$ & 1.5 \\
\hline
\end{tabular}

- The heat exchangers of the system form chains of two devices connected in series via ICC: a heat dissipator (radiator) and a heat source (any heat exchanger). Each such chain should be independently regulated and optimized for ICC flow rate.

- The heat exchangers of the system must enter independent (from the motor circulation circuit) circulation circuits.

- The circulation circuits of the heat exchangers and the motor must be combined (must have common points).

The use of the above provisions is primarily based on the fact that a closed loop, consisting of a heat dissipator and a heat source, can be optimized by changing the flow rate of ICC, which has been proved previously by various researchers $[13,14]$. When designing such cooling systems,

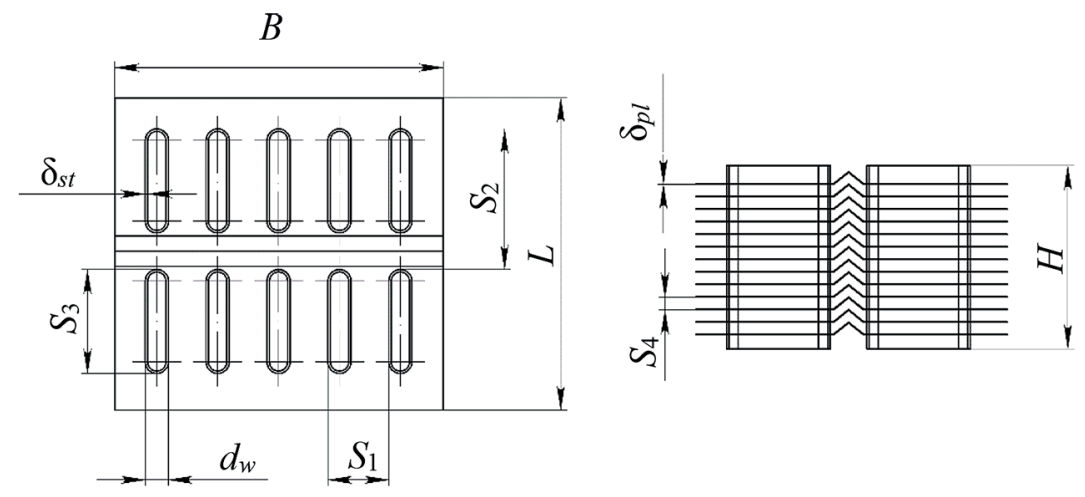

Fig. 3. Scheme of the heat transfer surface in the CAC and radiator R 
it was found that this position is true regardless of whether the circuit is the simplest closed or more complex, closing in a more complex way. A rational choice of ICC flow rate allows either to reduce the mass of the cores of heat exchangers with constant cooling efficiency, or to increase the cooling efficiency with a constant mass of cores, or to obtain both effects with a relatively lower intensity. Accordingly, heat exchangers cannot be placed in the circulation circuit of the engine, in which ICC flow rate does not change and is determined by completely different principles. Organized in this way, the cooling system can be called differently. The name «low-flow» fully characterizes this system and reflects its features. At the same time, such a feature as one ICC pump, as well as the union of two circulation circuits, may not be inherent in any low-flow rate systems. The organization of the circulation circuits makes it possible to ensure a significant local decrease in the temperature of the ICCs in the system, which is impossible for other types of systems. Local subcooling of ICC can provide low temperatures of charge air in the receiver, which is also a significant advantage of cooling systems organized based on of these rules. In particular, such systems are capable of providing in the engine receiver a charge air temperature corresponding to the extremely low values possible for recuperative cooling systems. The total mass of the cores of the heat exchangers of such cooling systems is less than for other recuperative systems, at equal temperatures of water, oil and air in the engine receiver. If the circulation circuits in the system have unifying points, then such a system has the potential for better regulation when changing engine loads and ambient temperatures.

If to implement the above recommendations, you can get a few different schemes of cooling systems for engines similar in purpose. In particular, it is possible to create systems with several radiators, when each heat source (CAC, oil cooler and cooler of hydraulic liquid) will have an individual radiator. Such structures theoretically have a lower mass, all other things being equal. In addition, for such systems, there are some advantages in controlling the temperature of the coolant. Nevertheless, in most cases, the practical manufacture of such systems and their elements eliminates the theoretical advantages provided by the complexity of the design, while a single radiator circuit is the simplest and provides the consumer with all the necessary parameters to a sufficient degree.
Certain features of system circuits are not excluded, depending on the purpose of the engines. In particular, for marine engines, it is possible to install a second core of the CAC, which is standing after first, and which is cooled directly by outboard water, to achieve lower temperatures of the cooled charge air.

Calculations and configurations of such cooling systems are quite simple, although they require some knowledge. These calculations can be roughly divided into three gradually increasing levels of complexity. The simplest, related to the first level, is the thermal calculation of the schematic diagram of the system. More complex, attributable to the second level, will be the thermal calculation of the system circuit, combined with the calculations of all heat exchangers. At the third level, a complete calculation of the system diagram is performed, combined with the calculations of the engine, heat exchangers and communications. Based on calculations of this level, it is possible to solve all engineering problems associated with the design of a cooling system.

To speed up the design process and give it the required accuracy, all the design elements of the system must be combined into a single mathematical model (design complex). In this complex, direct and feedback connections between interacting elements must be established.

During the calculation of the system scheme, the following assumptions were made.

- The heat transfer process at the design mode is steady-state.

- Heat losses in the sections of pipelines connecting heat exchangers are insignificant.

- Ambient temperatures are the same for all elements of the cooling system. The oil used in the engine system has properties that practically do not differ from those specified in the standard for the $\mathrm{M}-14 \mathrm{~W}_{2}$ brand (interstate standard 12337-84).

The basis for direct thermal calculation of the system scheme (first level) is a system of equations composed of:

- equations of heat balances for all heat exchangers and the entire cooling system;

- equations of heat fluxes in the system;

- equations of thermal balances at points of mixing of coolant flows;

- equations of mass balances at mixing points of coolant flows;

- equations of efficiency of all heat exchangers; 
- equations of the relationship between the efficiencies of all heat exchangers and their NTUs;

- expressions of the relationship between the NTU and the core masses of all heat exchangers.

Uniqueness conditions are added to the basis of system calculations. For the scheme shown in Figure 1, it is necessary to determine the values of 38 unknowns based on of the initial system of 33 equations that determine the conditions of heat transfer in the considered scheme of the cooling system. Obviously, for an unambiguous solution of the problem under consideration, it is necessary to set the values of five unknowns, and other unknowns can already be calculated only using the written system of equations. The solution of the problem is simplified if, as five free unknowns, we set the temperatures of the ICC downstream of the heat exchangers - the temperature after the CAC, $t_{w 2}$, the temperature of ICC after the $\mathrm{OC}, t_{w m 2}$, the temperature of ICC after the $\mathrm{H}$, $t_{w h 2}$, the efficiency of the CAC, $\eta_{c}$, and also the flow rate of the external coolant through the radiator, $G_{F}$. The choice of these parameters in a certain range can be quite easily localized and justified.

To change the temperatures $t_{w 22}, t_{w m 2}$ and $t_{w h 2}$, it is necessary to change the flow rates of the ICC through the CAC, OC and H. Accordingly, the total mass of the cores of the heat exchangers will change. On this basis, it is possible to optimize the consumption of ICC through heat exchangers.

Calculations of heat exchangers and the engine can be performed based on fairly common, well-known classical techniques that will satisfy the calculators with their accuracy and complexity, for example $[13,21]$. It should be noted that these named tasks were solved by the authors at a high level, considering the latest developments in these areas. Appropriate calculations are very complex structures. For example, a calculation program for each heat exchanger includes at least five subprograms. To calculate the engine parameters, a model was used based on the works of N.F. Razleitsev. Calculation of the pipelines of the system was carried out based on known methods of hydraulics. All methods were finalized by the authors considering the materials of their research, the characteristics of the engines and the elements of the cooling system under consideration.

The proposed calculation system is convenient for comparing various systems for which it is possible to plot the dependence of the total mass of the cores on some significant temperature, for example, on $t_{s}$. In this case, the total masses of the heat exchanger cores are compared at the same $t_{s}$, and the best system is selected.

\section{RESULTS AND DISCUSSION}

Consider the results of designing and optimizing a cooling system for an engine of type 12FSS $18.5 / 21.5$ with the parameters specified in Table 3. When calculating the cooling system, it was assumed that the system should provide the parameters of the engine coolants within the

Table 3. The main parameters of the nominal mode*

\begin{tabular}{|l|c|c|}
\hline \multicolumn{1}{|c|}{ Items } & Designation & Values \\
\hline Engine output $(\mathrm{kW})$ & $N_{e}$ & 2416 \\
\hline Engine speed $(\mathrm{rpm})$ & $n$ & 1900 \\
\hline Boost pressure $(\mathrm{bar})$ & $p_{c}$ & 5 \\
\hline Charge air flow $\left(\mathrm{kg} \mathrm{s}^{-1}\right)$ & $G_{c}$ & 5.37 \\
\hline Fan flow rate $\left(\mathrm{kg} \mathrm{s}^{-1}\right)$ & $G_{F}$ & 54 \\
\hline Ambient pressure $(\mathrm{bar})$ & $p_{0}$ & 1 \\
\hline $\begin{array}{l}\text { Maximum system ICC } \\
\text { pressure (bar) }\end{array}$ & $p_{\text {wmax }}$ & 2 \\
\hline Ambient temperature $\left({ }^{\circ} \mathrm{C}\right)$ & $t_{0}$ & 40 \\
\hline $\begin{array}{l}\text { Air temperature before } \\
\text { compressor }\left({ }^{\circ} \mathrm{C}\right)\end{array}$ & $t_{1}$ & 40 \\
\hline $\begin{array}{l}\text { Maximum system ICC } \\
\text { temperature }\left({ }^{\circ} \mathrm{C}\right)\end{array}$ & $t_{\text {wmax }}$ & 108 \\
\hline $\begin{array}{l}\text { Water temperature behind the } \\
\text { engine }(\text { max })\left({ }^{\circ} \mathrm{C}\right)\end{array}$ & $t_{\text {we2 }}$ & 108 \\
\hline $\begin{array}{l}\text { Air temperature in the } \\
\text { receiver }\left({ }^{\circ} \mathrm{C}\right)\end{array}$ & $t_{s}$ & 60 \\
\hline $\begin{array}{l}\text { Engine oil temperature } \\
\text { behind the engine }\left({ }^{\circ} \mathrm{C}\right)\end{array}$ & $t_{m 1}$ & 96 \\
\hline $\begin{array}{l}\text { Hydraulic fluid temperature } \\
\text { behind the system }\left({ }^{\circ} \mathrm{C}\right)\end{array}$ & $t_{h 1}$ & 96 \\
\hline ICC flow rate by pump $\left(\mathrm{kg} \mathrm{s}{ }^{-1}\right)$ & $G_{w e}$ & 24.4 \\
\hline Oil flow rate $\left(\mathrm{kg} \mathrm{s}{ }^{-1}\right)$ & $G_{m}$ & 14 \\
\hline Hydraulic flow rate $\left(\mathrm{kg} \mathrm{s}{ }^{-1}\right)$ & $G_{h}$ & 2 \\
\hline $\begin{array}{l}\text { Heat flow from engine } \\
\text { cylinders }(\mathrm{kW})\end{array}$ & $Q_{e}$ & 514 \\
\hline Heat flow from oil $(\mathrm{kW})$ & $Q_{m}$ & 230 \\
\hline Heat flow from hydraulics $(\mathrm{kW})$ & $Q_{h}$ & 29 \\
\hline
\end{tabular}

* Possible water temperatures behind the engine are 95-108 ${ }^{\circ} \mathrm{C}$; The air temperature in the receiver can vary within $50-60{ }^{\circ} \mathrm{C}$. 
limits specified in Table 3 at the nominal mode and for the most difficult operating conditions (summer, high ambient temperature).

To find the rational flow rate of ICC along the branches of the cooling system, the dependencies of $M_{\Sigma}$ (the sum of the masses of the cores of the heat exchangers of the cooling system) on various temperatures of the ICC were considered. In this case, it was assumed that rational costs should provide a minimum of $\mathrm{M}_{\Sigma}$ and, accordingly, a minimum of the price and dimensions of the system. The problem was solved by the method of descent along the coordinate with iterations along with the determined parameters.

In principle, a different target function can also be specified. In particular, it is possible to strive for certain sizes of CAC, etc. Accordingly, a strategy for searching for system parameters is built, considering the peculiarities of changing its parameters. It should also be considered that the difference in the extreme values of $M_{\Sigma}$ and the possible values of this quantity, which occur at the possible consumption of ICC along the branches of the system, can be much larger than that shown in the proposed example. The

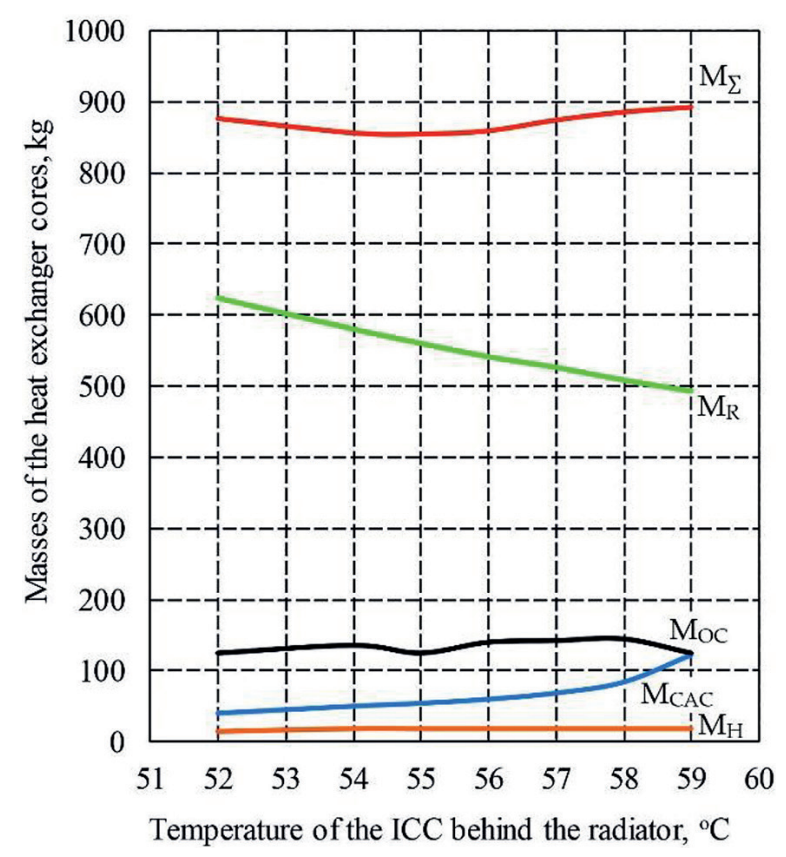

Fig. 4. Dependences of the masses of the heat exchanger cores on the temperature of the ICC behind the radiator, $t_{w 1}$, at $t_{w m 2}=69^{\circ} \mathrm{C}$, at the rated engine operating mode and $t_{0}=40^{\circ} \mathrm{C}: \mathrm{M}_{\mathrm{CAC}}$ - the mass of the core of one CAC; $\mathrm{M}_{\mathrm{R}}$ - the mass of the cores of two radiator blocks; $\mathrm{M}_{\mathrm{OC}}$ - the mass of the cores of all oil cooler blocks; $\mathrm{M}_{\mathrm{H}}$ - the mass of hydraulic fluid cooler cores; $M_{\Sigma}-$ total mass of heat exchanger cores difference depends on the initial parameters of the system, the method of choosing the flow rates of the ICC, the design of heat exchangers, etc.

According to the accepted method for solving the problem, at first, the dependence of the value of $\mathrm{M}_{\Sigma}$ on the values of tw 1 and other constant control temperatures in the system (temperatures of the charge air in front of the engine, ICC, oil and hydraulic fluid at the engine outlet). The value of the ICC temperature for OC, $t_{w m 2}$, in this case, was taken roughly, in the first approximation. It was assumed that it provided a close to the minimum value of $\mathrm{M}_{\Sigma}$, all other things being equal. The corresponding curves are shown in Figure 4.

The obtained dependence was used to establish the temperature value $t_{w 1}$ corresponding to the minimum of $\mathrm{M}_{\Sigma}$. With the set value of $t_{w 1}$, the dependence of $\mathrm{M}_{\Sigma}$ on $t_{w m 2}$ was plotted (Figure 5). Based on this dependence, the $t_{w m 2}$ value corresponding to the $M_{\Sigma}$ minimum was established in the following approximation.

The described procedures were repeated until the minimum value of $\mathrm{M}_{\Sigma}$ was obtained. It should be noted that with a change in the flow rate of ICC along the branches of the system (and the corresponding change in $t_{w 1}$ and $t_{w m 2}$ ), a significant change in the total masses of the cores in the system is provided. Because of the changes in ICC flow rates are associated with changes in $t_{w 1}$

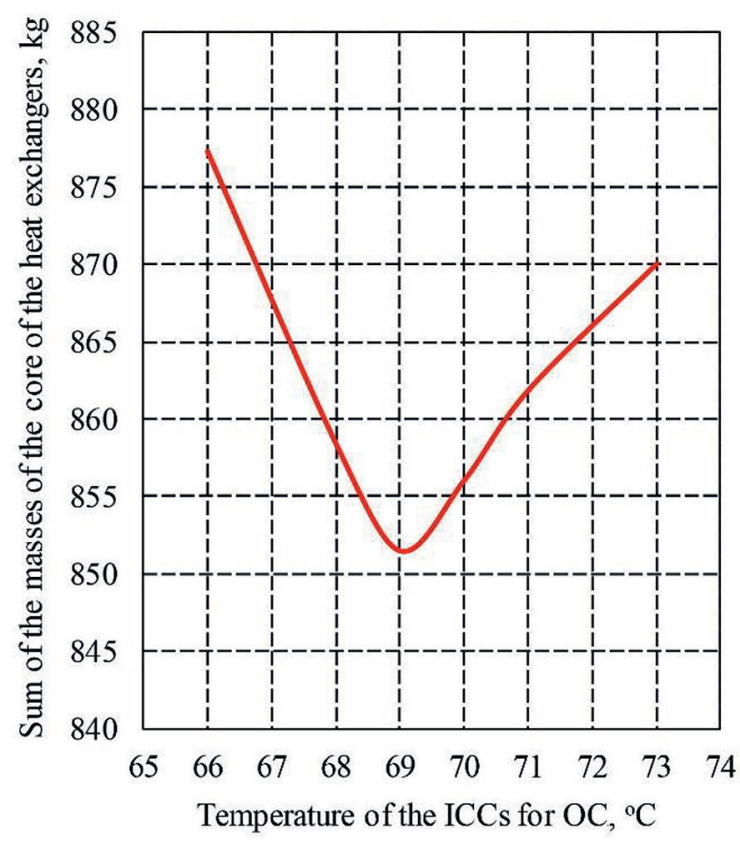

Fig. 5. The dependence of the sum of the masses of the core of the heat exchangers on the temperature of the ICC for $\mathrm{OC}$ at $t_{w 1}=55.5^{\circ} \mathrm{C}$ at the nominal engine operating mode and $t_{0}=40^{\circ} \mathrm{C}$ 


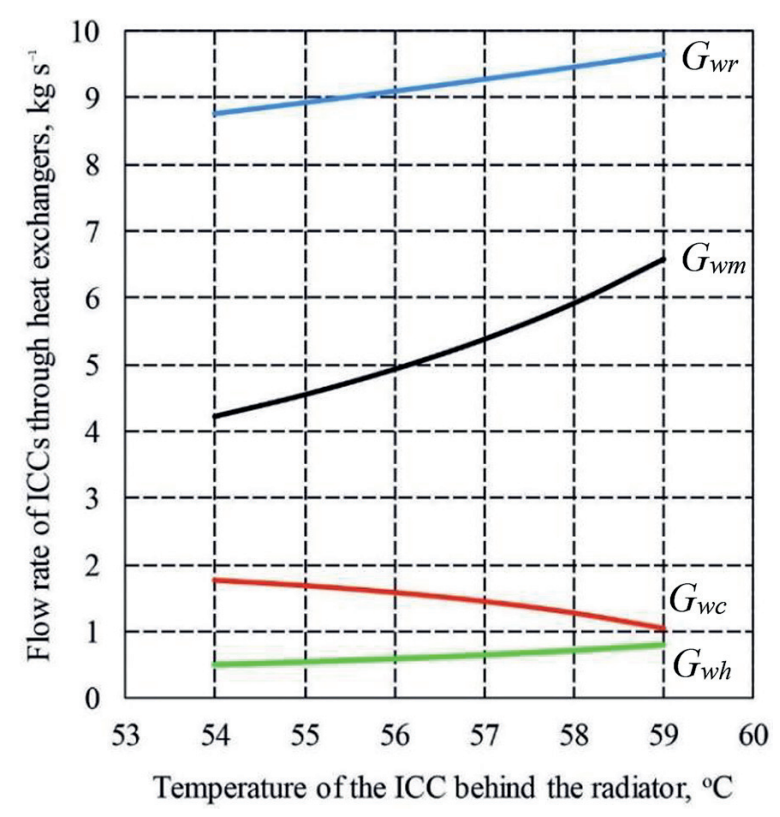

Fig. 6. The flow rate of ICCs through heat exchangers at $t_{w m 2}=69^{\circ} \mathrm{C}$ at nominal engine operation and $t_{0}=40^{\circ} \mathrm{C}$

and $t_{w m 2}$, here is possible to consider the change in $\mathrm{M}_{\Sigma}$ as a function of these temperatures. Especially significantly $\mathrm{M}_{\Sigma}$ changes in the $t_{w m 2}$ function, moreover, shown in Figure 5, the temperature range $t_{w m 2}$ is less than the limits that can be accepted with arbitrary system settings.

Considering the rate of change in the masses of cores from the temperatures of ICCs studied by the authors, it is assumed that the minimum sum of the masses of the cores of the system can be obtained at temperatures $t_{w 1} \approx 55.5^{\circ} \mathrm{C}_{\text {and }} \mathrm{t}_{w m 2} \approx$ $69^{\circ} \mathrm{C}$. The implementation of the corresponding direct calculations of the cooling system confirms this assumption. ICC flow rates through heat exchangers for rational temperatures can be determined from Figure 6.

In the reverse calculations of the cooling system, the real structural data of all heat exchangers are considered, which will inevitably differ from the «ideal» sizes obtained from indirect calculations. Accordingly, some discrepancy is obtained with the parameters of the cooling system obtained from indirect calculations. Typically, the temperatures of the coolants are obtained either with an «excess» or with a «disadvantage» in comparison with the set values, which have to be adjusted by rounding the sizes of the core of the heat exchangers considering the realities of the designs. In particular, for the conditions of real construction, it is necessary to design heat exchangers with an integer number of rows of tubes, it is necessary to observe the multiplicity of the number of transverse rows of tubes and the number of thermodynamic strokes along with the ICC, it is necessary to use an integer number of diaphragms, etc. When adjusting the «theoretical» dimensions, the resulting temperatures of the coolants provided by the cooling system are considered. Accordingly, the necessary rounding of the «theoretical» sizes of the cores is performed up or down.

Table 4 presents the results of the reverse calculation of the cooling system with the actual structural dimensions of the cores of the heat exchangers. Column I present the parameters of the engine cooling system for the nominal operating mode and extremely high (summer) ambient temperatures.

From column I of Table 4 it follows that the cooling system can provide a very low value of $t_{s}$ at the rated engine operating mode at high ICC temperature in front of the engine, as well as optimally high temperatures of oil and hydraulic fluid at the cooler inlet.

Column II shows the parameters of the system at the rated engine operating mode when the ambient temperature decreases. It is accepted that the air temperature in front of the radiator is -40 ${ }^{\circ} \mathrm{C}$, and the air temperature in front of the compressor is $-5{ }^{\circ} \mathrm{C}$ (air is taken by the compressor from the engine room). Temperature control is provided by changing the flow rate of cooling air $G_{\mathrm{B}}$, as well as changes in the flow rates of the ICC through the radiator and heat exchangers.

As can be seen from column II of Table 4, in the nominal engine operating mode, when the ambient temperature changes and when the ICC in the system is regulated, the air temperature in the engine receiver $t$ can remain almost unchanged. The oil and hydraulic fluid temperatures will remain unchanged $\left(t_{m 1}, t_{h 1}\right)$, and the water temperature behind the engine, $t_{\text {we2 }}$, will slightly decrease.

Column III of Table 4 gives the parameters of the cooling system during the transition of the engine to a fractional load (according to the locomotive characteristic) and the same air temperatures in front of the radiator and compressor. As it is seen, in this case, the temperature control of coolants in the system can practically provide the same air temperature in the engine receiver; the temperature of the ICC behind the engine $\left(t_{\text {we2 }}\right)$ will increase slightly (within acceptable limits), and the temperatures of the oil and hydraulic fluid $\left(t_{m 1}, t_{h 1}\right)$ will practically not change. 
Table 4. The results of the system calculations for various loads and ambient temperatures

\begin{tabular}{|c|c|c|c|c|}
\hline \multirow{2}{*}{ Designation } & \multirow{2}{*}{ Items } & \multicolumn{3}{|c|}{ Column Numbers } \\
\hline & & 1 & II & III \\
\hline$N_{e}$ & Engine output (kW) & 2416 & 2416 & 604 \\
\hline$n$ & Engine speed (rpm) & 1900 & 1900 & 1242 \\
\hline$Q_{e}$ & Heat flow in ICCs from engine parts (kW) & 514.0 & 514.0 & 221.0 \\
\hline$Q_{m}$ & Heat flow to oil (kW) & 230.0 & 230.0 & 102.0 \\
\hline$Q_{c}$ & Charge air heat flow (kW) & 431.26 & 311.46 & 94.84 \\
\hline$Q_{h}$ & Heat flow from hydraulics $(\mathrm{kW})$ & 29.80 & 29.80 & 29.80 \\
\hline$G_{F}$ & Fan flow rate $\left(\mathrm{kg} \mathrm{s}^{-1}\right)$ & 54.0 & 8.30 & 3.25 \\
\hline$G_{c}$ & Charge air flow $\left(\mathrm{kg} \mathrm{s}^{-1}\right)$ & 5.37 & 5.37 & 1.94 \\
\hline$G_{m}$ & Oil consumption $\left(\mathrm{kg} \mathrm{s}^{-1}\right)$ & 14.0 & 14.0 & 14.0 \\
\hline$G_{h}$ & Hydraulic flow rate $\left(\mathrm{kg} \mathrm{s}^{-1}\right)$ & 2.0 & 2.0 & 2.0 \\
\hline$G_{\text {we }}$ & ICC consumption through the pump $\left(\mathrm{kg} \mathrm{s}^{-1}\right)$ & 24.40 & 24.40 & 24.40 \\
\hline$G_{w r}$ & ICC consumption through radiator $\left(\mathrm{kg} \mathrm{s}^{-1}\right)$ & 5.70 & 5.80 & 2.12 \\
\hline$G_{w c}$ & ICC consumption through one CAC $\left(\mathrm{kg} \mathrm{s}^{-1}\right)$ & 1.88 & 1.88 & 0.63 \\
\hline$G_{w m}$ & ICC consumption through $\mathrm{OC}\left(\mathrm{kg} \mathrm{s}^{-1}\right)$ & 1.62 & 1.70 & 0.51 \\
\hline$G_{w h}$ & ICC consumption through $\mathrm{H}\left(\mathrm{kg} \mathrm{s}^{-1}\right)$ & 0.33 & 0.35 & 0.37 \\
\hline$G_{w b}$ & ICC consumption through bypass $\left(\mathrm{kg} \mathrm{s}^{-1}\right)$ & 18.70 & 18.60 & 22.28 \\
\hline$p_{c}$ & Boost pressure $(\mathrm{kPa})$ & 500.0 & 500.0 & 230.0 \\
\hline$t_{0}$ & Air temperature in front of the radiator $\left({ }^{\circ} \mathrm{C}\right)$ & 40.0 & -40.0 & -40.0 \\
\hline$t_{1}$ & Air temperature before compressor $\left({ }^{\circ} \mathrm{C}\right)$ & 40.0 & 5.0 & 5.0 \\
\hline$t_{c}$ & Air temperature behind the compressor $\left({ }^{\circ} \mathrm{C}\right)$ & 271.60 & 210.70 & 99.65 \\
\hline$t_{s}$ & Air temperature in the receiver $\left({ }^{\circ} \mathrm{C}\right)$ & 50.41 & 50.95 & 51.01 \\
\hline$t_{\mathrm{a} 21}$ & Air temperature behind the radiator $\left({ }^{\circ} \mathrm{C}\right)$ & 62.20 & 90.10 & 97.05 \\
\hline$t_{w e 1}$ & ICC temperature in front of the engine $\left({ }^{\circ} \mathrm{C}\right)$ & 89.36 & 85.18 & 95.05 \\
\hline$t_{\text {we2 }}$ & ICC temperature behind the engine $\left({ }^{\circ} \mathrm{C}\right)$ & 94.39 & 90.21 & 97.21 \\
\hline$t_{w 1}$ & ICC temperature behind the radiator $\left({ }^{\circ} \mathrm{C}\right)$ & 43.94 & 45.55 & 46.82 \\
\hline$t_{\mathrm{w} 2}$ & ICC temperature per $\mathrm{CAC}\left({ }^{\circ} \mathrm{C}\right)$ & 71.38 & 65.37 & 64.93 \\
\hline$t_{\text {wh2 }}$ & ICC temperature per $\mathrm{H}\left({ }^{\circ} \mathrm{C}\right)$ & 65.49 & 65.87 & 66.31 \\
\hline$t_{w m 2}$ & ICC temperature per $\mathrm{OC}\left({ }^{\circ} \mathrm{C}\right)$ & 77.82 & 77.84 & 95.02 \\
\hline$t_{m 1}$ & Oil temperature before $\mathrm{OC}\left({ }^{\circ} \mathrm{C}\right)$ & 95.56 & 95.64 & 95.28 \\
\hline$t_{m 2}$ & Oil temperature per $\mathrm{OC}\left({ }^{\circ} \mathrm{C}\right)$ & 87.69 & 87.78 & 91.79 \\
\hline$t_{h 1}$ & The temperature of the hydraulic before $\mathrm{H}\left({ }^{\circ} \mathrm{C}\right)$ & 94.91 & 95.07 & 95.43 \\
\hline$t_{h 2}$ & The temperature of the hydraulic after $\mathrm{H}\left({ }^{\circ} \mathrm{C}\right)$ & 87.73 & 87.89 & 88.31 \\
\hline CAC & \multicolumn{4}{|l|}{ Charge air cooler } \\
\hline$b$ & The number of strokes thermodynamic & 12.0 & 12.0 & 12.0 \\
\hline$\eta_{c}$ & CAC efficiency & 0.97 & 0.97 & 0.92 \\
\hline$\Delta p_{c}$ & CAC resistance in the air $\left(\mathrm{mm} \mathrm{H}_{2} \mathrm{O}\right)$ & 107.6 & 105.6 & 35.1 \\
\hline$\Delta p_{\mathrm{wc}}$ & $\mathrm{CAC}$ resistance for $\mathrm{ICC}(\mathrm{kPa})$ & 31.47 & 31.47 & 31.47 \\
\hline$L$ & Length along the air $(\mathrm{mm})$ & 516.0 & \multirow{3}{*}{\multicolumn{2}{|c|}{ for one core }} \\
\hline$B$ & Front width $(\mathrm{mm})$ & 308.0 & & \\
\hline$H$ & The distance between the tube sheets $(\mathrm{mm})$ & 280.0 & & \\
\hline$M_{c}$ & Core weight without boards $(\mathrm{kg})$ & \multicolumn{3}{|c|}{47.92} \\
\hline $\mathrm{R}$ & \multicolumn{4}{|l|}{ Radiator } \\
\hline$b$ & The number of strokes thermodynamic & 7.0 & 7.0 & 7.0 \\
\hline$\eta_{R}$ & Radiator efficiency & 0.93 & 1.0 & 1.0 \\
\hline$\Delta p_{\mathrm{R}}$ & Air resistance $\left(\mathrm{mm} \mathrm{H}_{2} \mathrm{O}\right)$ & 54.04 & 54.04 & 54.04 \\
\hline$\Delta p_{w R}$ & $\mathrm{ICC}$ resistance $(\mathrm{kPa})$ & 18.21 & 18.21 & 18.21 \\
\hline$L$ & Length along the air $(\mathrm{mm})$ & 151.0 & \multirow{3}{*}{\multicolumn{2}{|c|}{ for one block }} \\
\hline$B$ & Front width $(\mathrm{mm})$ & 1801.0 & & \\
\hline$H$ & The distance between the tube sheets $(\mathrm{mm})$ & 1013.0 & & \\
\hline$M_{R}$ & Core weight without boards $(\mathrm{kg})$ & \multicolumn{3}{|c|}{295.50} \\
\hline $\mathrm{OC}$ & \multicolumn{4}{|l|}{ Oil cooler } \\
\hline$b_{r}$ & Number of counter flow elements & 2.0 & 2.0 & 2.0 \\
\hline
\end{tabular}


Cont. Table 4. The results of the system calculations for various loads and ambient temperatures

\begin{tabular}{|c|c|c|c|c|}
\hline$\eta_{m}$ & OC efficiency & 0.66 & 0.64 & 0.99 \\
\hline$\Delta p_{m}$ & Oil resistance $(\mathrm{kPa})$ & 17.36 & 16.71 & 41.32 \\
\hline$\Delta p_{w m}$ & ICC resistance $(\mathrm{kPa})$ & 3.79 & 4.16 & 0.42 \\
\hline$D_{i}$ & Case diameter inner $(\mathrm{mm})$ & 380.0 & \multicolumn{2}{|c|}{ for all blocks } \\
\hline$L$ & Tube length overall $(\mathrm{mm})$ & 1889.0 & \multicolumn{2}{|c|}{ total tube length } \\
\hline$M_{o C}$ & The mass of cores of all elements $(\mathrm{kg})$ & \multicolumn{3}{|c|}{154.72} \\
\hline $\mathrm{H}$ & \multicolumn{4}{|l|}{ Hydraulic fluid cooler } \\
\hline$b_{r}$ & Number of counterflow elements & 1.0 & 1.0 & 1.0 \\
\hline$\eta_{h}$ & Efficiency $\mathrm{H}$ & 0.42 & 0.41 & 0.40 \\
\hline$\Delta p_{h}$ & Hydraulic resistance $(\mathrm{kPa})$ & 3.03 & 2.94 & 2.82 \\
\hline$\Delta p_{w h}$ & ICC resistance $(\mathrm{kPa})$ & 6.87 & 7.67 & 8.29 \\
\hline$D_{i}$ & Case diameter inner $(\mathrm{mm})$ & 209.0 & \multicolumn{2}{|c|}{ for all blocks } \\
\hline$L$ & Tube length overall $(\mathrm{mm})$ & 528.0 & \multicolumn{2}{|c|}{ total tube length } \\
\hline$M_{H}$ & The mass of cores of all elements $(\mathrm{kg})$ & \multicolumn{3}{|c|}{16.47} \\
\hline $\mathrm{M}_{\Sigma}$ & $\begin{array}{l}\text { The sum of the masses of all the cores of the } \\
\text { system }(\mathrm{kg})\end{array}$ & \multicolumn{3}{|c|}{858.03} \\
\hline$\eta_{0}$ & Efficiency of an air cooling system & 0.96 & 0.64 & 0.35 \\
\hline
\end{tabular}

The temperatures, obtained by the described control methods, are given here as an example. With the known optimal values of the temperatures of the coolants for these or other modes, it is possible to provide more suitable values of the control temperatures of the coolants by regulations, which are very likely to be close to those presented in Table 4.

Systems with additional cooling of the charge air by refrigeration machines, capable of providing a competitive advantage, are very cumbersome. In this regard, it is possible to carefully suggest their possible use only for ship cooling systems, which are relatively less compact. Such systems require intensive cooling of additional elements. As a basis for such systems, the considered scheme can be also successfully applied.

\section{CONCLUSIONS}

The scheme of this system can be used as a basis for creating effective cooling systems for modern engines, and the set of principles for organizing systems given in the article can be used as a guide in the development of liquid cooling systems for modern engines.

The cooling system, built according to the named principles, is capable of providing the maximum possible reduction in the charge air temperature for recuperative systems. At a given air temperature in the engine receiver, it is possible to provide the minimum possible, for the same conditions, the sum of the masses of the heat exchanger cores. The cooling system layout is quite simple, there are no additional units in the system, and the designs of heat exchangers are close to traditional ones. When regulating the system under consideration, rational temperatures of the engine coolants are provided at any possible engine loads and changes in ambient temperatures.

The simplest finding of the minimum masses of the heat exchanger cores is provided by solving the corresponding system of equations when the allocations of the temperatures of the ICC behind the heat exchangers is are provided as free factors.

\section{REFERENCES}

1. Eitel J. Engine Cooling Systems and Cooling Components for Euro 5 Commercial Vehicles. ATZ worldwide. 2008; 110: 56-59.

2. Application \& Installation Guide Cooling Systems. CAT, Caterpillar, BUILT FOR IT; 2016.

3. Ap N.-S., Jouanny P., Potier M., Genoist J. Ultimate Cooling System for New Generation of Vehicle. SAE Technical Paper Series. 2005.

4. Cipollone R., Di Battista D., Gualtieri A. A novel engine cooling system with two circuits operating at different temperatures. Energy Conversion and Management. 2013; 75: 581-592.

5. Ovcharenko S., Balagin O., Balagin D. Cooling system operation efficiency of locomotive diesel engine. IOP Conference Series: Earth and Environmental Science, Energy Management of Municipal Transportation Facilities and Transport - EMMFT 2017 10-13 April 2017, Far Eastern State Transport University, Russian Federation 2017, 90, 2-7. 
6. Nutt R. A., Poehlman R. F. Cooling System Requirements for Advanced Diesel Engines. SAE Technical Paper Series 820984; 1982.

7. Sekar R.R. Trends in Diesel Engine Charge Air Cooling. SAE Transactions Series 820503. 1982; 91: 2102-2113.

8. Mollenhauer K., Tschoeke H. Handbook of Diesel Engines. Springer-Verlag Berlin, Heidelberg; 2010: 291-338.

9. Hua S., Huang R., Zhou P., Cheng W., Jia L. Experiments on the influence of cooling conditions on thermal balance and thermal state for a heavy-duty natural gas engine. Paper presented at the ASME 2015 Internal Combustion Engine Division Fall Technical Conference, Houston, Texas, USA 2015, 1015-1023.

10. Ap N.S., Tarquis M. Innovative engine cooling systems comparison. SAE Technical Papers. 2005.

11. Mathur G.D., Hara J., Iwasaki M., Meguriya Y. Development of an innovative energy efficient compact cooling system "SLIM". SAE Technical Papers; 2012.

12. Stanivuka T., Lalica B., Mikulicica J.Z., Sundovb M. Simulation Modelling of Marine Diesel Engine Cooling System. Transactions on Maritime Science. $2021 ; 10(1)$ : 112-125.

13. Kays W.M., London A.L. Compact Heat Exchangers. Mc Graw - Hill Book Company, New York; 1964.

14. Eastwood J.C. Liquid-Coupled Indirect-Transfer Exchanger Application to the Diesel Engine. Journal of Engineering for Power. 1979; 101(4): 516-523.
15. Lee C.M., Jeon T.Y., Jung B.G., Lee Y.C. Design of Energy Saving Controllers for Central Cooling Water Systems. Journal of Marine Science and Engineering. 2021; 9(513): 1-15.

16. Jose J.T., Dunne J.F., Pirault J.-P., Long C. A. Spray evaporative cooling system design for automotive internal combustion engines. Paper presented at the ASME 2018 Internal Combustion Engine Division Fall Technical Conference, San Diego, California, USA 2018.

17. Hamdy M., Askalany, A. A., Harby K., Kora N. An overview on adsorption cooling systems powered by waste heat from internal combustion engine. Renewable and Sustainable Energy Reviews. 2015; 51: $1223-1234$

18. Galindo J., Dolz V., Tiseira A., Ponce-Mora A. Thermodynamic analysis and optimization of a jet ejector refrigeration cycle used to cool down the intake air in an IC engine. International Journal of Refrigeration. 2019; 103: 253-263.

19. Zegenhagen M.T., Ziegler F. Feasibility analysis of an exhaust gas waste heat driven jet-ejector cooling system for charge air cooling of turbocharged gasoline engines. Applied Energy. 2015; 160: 221-230.

20. Novella R., Dolz V., Martín J., Royo-Pascual L. Thermodynamic analysis of an absorption refrigeration system used to cool down the intake air in an Internal Combustion Engine. Applied Thermal Engineering. 2017; 111: 257-270.

21. Ezgi C. Basic Design Methods of Heat Exchanger. Heat Exchangers - Design, Experiment and Simulation. 2017: 9-35. 